\title{
Reflexive Debate on Use of Philosophy in Scientific Research
}

\author{
Manoah Muchanga* \\ University of Zambia
}

*Corresponding Author: Manoah Muchanga, University of Zambia

\begin{abstract}
How should philosophy be used in scientific research? is the question addressed in this paper. The aim of this desktop research was to critically contribute to the already ongoing debate around the use of philosophy in scientific research and to propose a user friendly framework on how to integrate philosophical decisions with methodological decisions. This paper argues that the content and length of a research does not make it scientific, but its philosophical foundation and related methodologies. It also shows that use of philosophy in research is not merely a recitation, repetition and dumping of borrowed words, but a reasoned and careful re-contextualization of philosophical assumptions to apply them to one's own research thesis. There is also no such a thing as epistemological and ontological monovalence because there are many ways of creating and understanding reality and, moreover, which paradigmatic framework is 'better' partly depends on the research question(s) one seeks to answer. Only if we understood each philosophy and its assumptions, would we be in a better position to challenge them and, reflexively think differently.
\end{abstract}

Key words: Philosophy, Epistemology, Ontology, Research, Education, Science

\section{INTRODUCTION}

The probity, perspicacity and profundity of research is more dependent on the onto-espistemic process than its methodologic context because the latter is dependent on the former, influencing research conduct models and implementation process. Although Bless and Achola (1990) argue that the content of the subject matter does not make it scientific, but its methodology, such a perspective has to be approached with critical reflexivity and constructive confrontation given that, there is no methodology without a legitimate core parent from the philosophies of science. Scientific researches that are framed within specific philosophical landscapes have much to contribute to expansive scientific and educational research dialogues than those that are devoid of it (Saunders et al., 2007). Social and natural science disciplines have witnessed a myriad of ontological confrontations, each claiming to offer a superior analytic framework for making sense of core issues in various disciplines, whilst denigrating the other(s). What most consistently divide these schools of thought are not their substantive claims about natural and social phenomena, but their metatheoretical assumptions (philosophical discussion of the foundations, structure, or results of some theory) concerning how such claims should be developed and supported (Hartwig, 2010). The crux of the matter is, 'what is' in one discipline, is 'what is not' in another, depending on the ontological position taken by individual researchers. Even those who presumptuously claim onto-espistemic objectivity and purism are subject to some cryptic value-ridden influences given that, they are guided by either explicit or implicit axiological assumptions in their methodological decisions, which truthfully speaking, rule out concrete universality of objectivity. Whatever the discipline may be, however aggrandized or denigrated its academic panoply, every researcher from any field must realize that, an important part of any academic research process involves ensuring that the methodology and methods used are consistent with the ontological and epistemological assumptions of a particular philosophy of science (Guba, 1990). Saunders et al. (2007:100) add that, "questions of research design and methods are secondary to questions of paradigm or philosophy". This chapter discusses the inter-relationship that exists among the philosophical approaches and methodological decisions.

Philosophy comes from the Greek word Philosophia (Taneja, 2008). It is made up of two words, that is, philia (love) and Sophia (wisdom). Etymologically, philosophy turns out to be the love of wisdom and whoever loves this wisdom is a philosopher (Ibid). Makumba (2009) defines philosophy as critical thinking, which leads to the knowledge of things through their ultimate cause. It is also a 
critical pursuit of the truth and knowledge. To philosophize, therefore, is to reflect on the totality of things we encounter with a view to understanding the reason for their existence (Makumba, 2009). As a philosophical researcher, one is under obligation to delineate the cause of reality and to investigate and question all things that relates to research. In the words of Aristotle, all men by nature desire to know. This natural desire by human beings to know the truth is one of the main bedrocks of philosophy (Burr and Goldinger, 2012). Since philosophy is an attempt to satisfy this thirst for knowledge, it is rightly positioned and significant in scientific research in general. The problem addressed by this desktop research is premised on the misunderstandings and scientific dystopia that scientific and social researchers especially the beginners may be experiencing regarding integration of philosophy in the research processes.

\section{Philosophical Approaches In ReSEARCH}

Academic researchers have witnessed many battles among contending approaches, each claiming to offer a superior analytic framework for making sense of core issues in various disciplines. What most consistently divides various schools of thought is not their substantive claims about specific phenomena, but their metatheoretical assumptions (Philosophical discussion of the foundations, structure or results of some theory) concerning how such claims should be developed and supported (Lot-Sisitka et al., 2013). In research, philosophies are also known as paradigms or research traditions (Saunders et al., 2007). We need to be alert to such variations in wording by different scholars. Generally, there are two broad approaches of philosophies or paradigms namely, positivism and postpositivism. The former supports quantitative approaches whereas the latter is qualitative in nature.

\subsection{Positivism and Post-Positivism}

Positivism is quantitative in nature and focuses on traditional, empirical and experimental research approaches. Some of its major proponents include John Locke, Emile Durkheim and Augustine Comte (Taneja, 2008). The basic belief of positivism is realist ontology, that is, the belief that there exists a reality 'out there' driven by immutable or infallible natural laws (Guba, 1990). Its core business is to discover 'true' nature of reality and how it 'truly' works. Once committed to a realist ontology, the positivist is constrained (non-transgressive) to practice an objectivist epistemology. The 'highly esteemed' methodology in positivism is empirical experimentalism or as close an approximation thereto as could be managed (Guba, 1990).

Post-positivism implies 'after positivism'. It is also known as post-empiricism. It is a philosophical model of scientific inquiry that critiques and amends positivism. It was mainly advanced by Huberman, Kant, Wittgenstein (Guba, 1990). Post-positivism affirms that theories, background, knowledge and values of the researcher can influence what is observed. Post-positivists believe that human knowledge is based not on unchallengeable, rock-solid foundations, but upon human construction of knowledge. In post-positivism, there is a belief in 'reality' just like positivism does. However, it is held that 'reality' can only be known imperfectly and probabilistically because it is based on human construction (O'Leany, 2004). Unlike positivism which tends to be methodologically conservative, post-positivism offers fairly transgressive and liberative methodological options (Price, 2013). Investigating one's own epistemologies and understanding regarding how they affect him or her as a researcher is an essential part of the post-positivist approach. As part of this investigation, you come to some understanding of how people construct and maintain perceptions of the world. Examining our epistemology involves looking at the underlying assumptions we use to make sense of our day-to-day lives. 'You cannot claim to have no epistemology. Those who so claim have nothing but a bad epistemology' (Bateson, 1977: 13). A good researcher always remembers to state the epistemological and ontological assumptions that govern his or her research. These two philosophical approaches constitute specific paradigms (it is not the focus of this paper to discuss such specific philosophies) from which one would carefully choose depending on the nature of his or her research. Each specific philosophy, either from positivism or post-positivism, is guided by assumptions that can inform research in different practice contexts. Although axiological assumptions (to be summarized towards the end of this paper) also influence each paradigm, the main set of assumptions is divided into two, namely, epistemology and ontology (Burr and Goldinger, 2012).

\subsection{Epistemological Dimension of Philosophy}

In the science of research, epistemology is made up of two Greek words, that is, Episteme which is a Greek word for knowledge and Logos, a Greek word for 'reason' or 'discourse'. Literally, 
epistemology is a reasoned dialogue about knowledge. It is also defined as philosophical reasoning about knowledge and the grounds on which knowledge is created (Makumba, 2009). Epistemology is also known as the "theory of knowledge," and it is a branch of philosophy that studies the nature of knowledge, particularly its foundations, scope, limits and validity. It questions what knowledge is and how it can be acquired, as well as the extent to which any given subject or entity can be known (LotzSisitka et al., 2012). Epistemology is centered on analyzing the nature of knowledge and how it relates to connected notions such as truth, belief and justification. Epistemology is a study of how people or systems of people know things and how they think they know things (Keeney, 1983:13). It is, thus, concerned with the nature of knowledge, what constitutes valid knowledge, what can be known and who can be a knower.

\subsection{Ontological Dimension of Philosophy}

Ontology is the philosophical explanation about understandings of 'reality', it comes from the Greek word 'ontos' which means 'being', and 'logos' which, as earlier mentioned is the Greek word for 'study' (Bhaskar, 2012). Ontology is, therefore, the philosophical study of the nature of being, becoming, existence or reality, as well as the basic categories of being and their relations. It seeks to answer questions concerning what entities exist or can be said to exist, and how such entities can be grouped, related within a hierarchy and subdivided according to similarities and differences (Burr and Goldinger, 2012). Ontological views influence epistemology and, eventually, methodological approach and methods of research. Therefore, an important part of the research process involves ensuring that the methodology and methods used are consistent with the ontological and epistemological assumptions of the research.

\section{Reflective Questions:}

1. What is wrong with the positivist philosophical framework? How can the 'wrongs' be corrected?

2. Critically analyze shortcomings of post-positivistic thinking in research. How would you prevent such shortcomings from compromising the credibility of your research?

3. Based on the above paragraphs, would someone be justifiable to say, "I can do research without expounding its epistemic foundation?" Give reason(s) for your thought.

4. What Philosophical approach have you used in your past and ongoing researches? Why?

5. Discuss the importance of a well elaborated ontology in a research? Is it logical to venture into methodological descriptions before ontological description? Why?

\section{USE OF PHILOSOPHY SCIENTIFIC RESEARCH}

Substantive research that is conceptualized and pursued within paradigms has much to contribute to education research (Lotz-Sisitka et al., 2013). Before a more expansive dialogue can take place among heterogeneous community of scholars, it is useful first to have some philosophical dialogue about the basis of concepts (Namafe and Muchanga, 2017). Moreover, a common theoretical language and a common set of methods and evaluative standards predicated on a common meta-theoretical perspective must be ascertained (O'Leany, 2004). Such a set of initial shared understandings allows for focused research that can be easily coded, compared, and cumulated within distinct research traditions.

Philosophy in scientific research also facilitates the generation of parsimonious and rational arguments as well as stocks of knowledge that can help to operationalise, delimit and re-contextualize further research without having to reinvent the wheel each time (Price, 2013). Parsimony refers to the explanation of phenomena in the most precise and straightforward way possible. Rationalism is a scientific principle that knowledge should be based on clarity of thought (Cohen et al., 2000). These assumptions are inherently useful in interpretation of data collected from a study and in the final creation of knowledge relevant to scientific research. Although it is usually received with repulsive feeling especially among novice scholars, 'academic confrontation' is a critical recipe in one's intellectual growth. Location of research within a particular philosophical landscape paves way for 'creative confrontations' (Lichbach, 2007: 274) between paradigms. Such creative and critical 
confrontations spur intellectual progress within a paradigm by motivating its adherents to refine their theories and narratives in response to challenges from others. Why do scholars then feel offended when challenged by opposing views? The simplest and quickest reason could be that their thoughts have not yet settled within a particular philosophical foundation which they themselves may sometimes have not clarified to enable them appreciate minds that think differently.

\section{Reflective Questions:}

1. How does philosophy shape one's thinking in research?

2. Discuss the importance of 'creative confrontation' in environmental research.

3. What philosophies govern your day-to-day academic thinking and practice? Why?

4. In what ways have your researches reflexively shaped your adopted philosophy?

Philosophy is also a 'great parent' of whatever methodology and method one would think of. It is therefore, unjustifiable and illogical for one to say "I am not using any philosophy" or "I am comfortable without it". Upholding such ideas is as good as saying "I am not using any methodology in my research". The principle is, if you cannot adopt and re-contextualize a philosophy, create one. Saunders et al. (2007:100) argue that questions of methods are secondary to questions of paradigm, which is defined as the basic belief system or world view that guides the investigation, not only in choices of methods, but also in ontologically and epistemologically fundamental ways. Therefore, if we think we have made scientific methodological decisions without first considering who their 'philosophical parent' is, we are basically doing what I would call Illegitimate Methodological Decision (IMD), which would also lead to Illegitimate Science (IS). In one of the research conferences I attended in 2012 in South Africa, I heard one research scholar from Zambia saying: "A research without a 'philosophical garment' is like a newly born child without Napkins" Isn't it embarrassing to have a newly born child without napkins? Similarly, isn't it embarrassing to do a new research without 'philosophical napkins'? From the principle of natural law, is it possible for a child to exist parents? Likewise, is it possible to talk about methodology and even methods without first talking about their 'parents'? Aren't methods influenced by epistemology? Isn't the nature of research knowledge first influenced by ontology? Where then would one do a research without a philosophical basis? "I just graduated without one!", but I would contra-pose in line with Bates' (1977) and Bhaskar's (2012) stance that, you had a philosophy, only that, it was a 'bad one'.

This brings me to a point where I disagree with Bless and Achola's (1990) assertion that, "the content of a subject matter does not make it scientific, but its methodology". Instead, it would be lucid to say 'the content of a subject matter does not make it scientific, but its paradigmatic framework, because that is what gives birth to a methodological framework'. Methodology does not exist on its own, it blooms from a certain philosophical landscape. As earlier mentioned, philosophy is the love of wisdom and, by its definition, wisdom is not the same as knowledge, it is more than knowledge. That is why research is not merely a recitation and dumping of facts obtained from other scholars, but rather a training of the mind to think and re-think so as to bring about new knowledge. According to Taneja (2008), wisdom includes knowledge and goes beyond it to find relationships and to unearth implications. It implies a 'mature reflection' (one of the requisites when carrying out research) about any problem in its complete perspective before bringing it out for public consumption. It is, therefore, significant to consider philosophy, whether it is implicit or explicit as a tool to conduct a successful and mature research. Philosophy gives us wisdom that enables us to escape the 'Let me make a mistake or write whatever I deem to be right in my own ways, so that I can be corrected during presentation' syndrome. Embracing philosophical landscapes in our researches would therefore, help us develop personal critical reflexivity, question and even re-question our ideas before they are questioned by others.

Reflective question: Why is philosophical thinking important in environmental research?

\section{Misapplication of Philosophy in Research}

From a very critical point of view, non-application of philosophy in research is more tolerable than its misapplication. Many researchers frequently commit what I would call 'Methodological Adultery' 
where a philosophy and subsequent methodologies scientifically incompatible or barely compatible with the nature of a research topic are adopted and imposed on the research. It may make sense at individual level, but the question would be "how sensible would that sense be to other readers in the 'know'?" Usually this happens where a researcher does not have enough information about application of research philosophy or he or she does not want to boggle his or her mind with too much reading. "I will use this philosophy because that is the only one I have found" or "I will use this philosophy because it sounds well in my ears and communicates with my mind". The best practice is to ask whether your research idea will be compatible with the adopted philosophy. Always ask yourself, "have I really read widely concerning existing philosophies, and have I compared them thoroughly before adopting this or that philosophy?" The idea is that you cannot only read one philosophy and get settled for it because chances are high that you would commit incompatibility errors. The other common source of temptation is where whatever philosophy you read about seems to perfectly match your research topic. Some of the commonest sentiments from those who suffer from this challenge include "I can work with this philosophy", "even this other one is okay for my research" "I can pick on any of these philosophies because they all make sense". This can be compared to a man who says "I can pick on any of these women to be a wife because they all make sense", that would be a terrible mistake because even among polygamists, there is always one wife who really make sense more than the other(s). Therefore, whenever every philosophy you read makes sense to you for your research, just know that you have not yet found one, and that research ideas are still maturing in your mind. Certain philosophies are inextricably linked, yet not the same, extra care and reflectivity must be exercised. In Figure 1 below I propose a framework that one may use to avoid misapplication of philosophies in research.

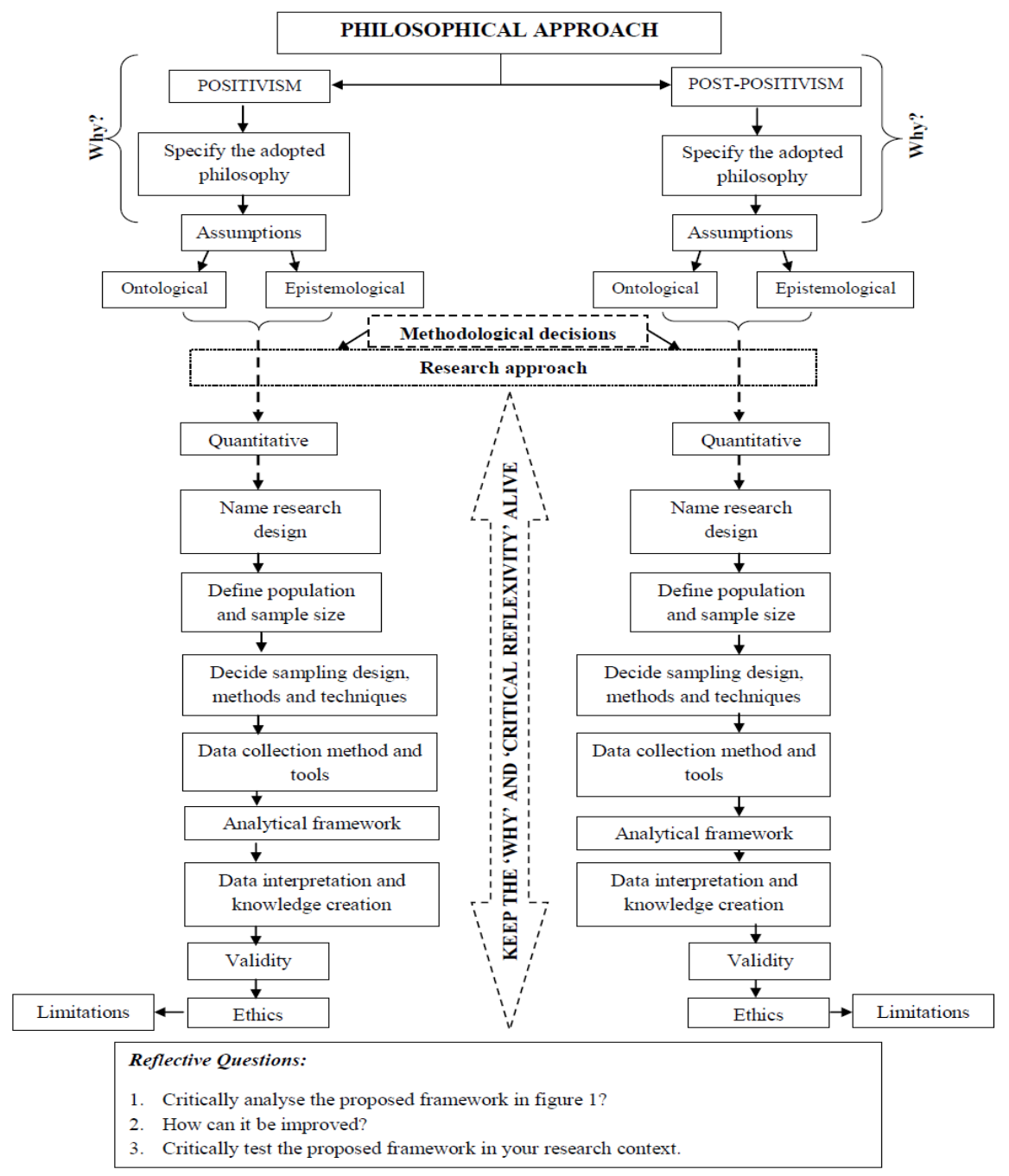

Figure1. Proposed framework on integration of philosophy and methodological decisions

From this discourse, it is evident that research philosophy relates to the development of knowledge and the nature of that knowledge. It also constitutes important assumptions about the way in which we 
view the world. Research philosophy is mainly thought about in three ways namely epistemology, ontology and axiology. The latter has not been discussed in this chapter, but it simply refers to a branch of philosophy that studies judgements about values (Saunders et al., 2007). The role which our values play in all stages of the research process is of great significance if we wish our research results to be credible. Choosing one philosophy rather than the others suggests that one of the philosophies is more important than the others to a particular research context. Your choice of a philosophical approach is a clear reflection of the values you place on it. Axiology would also influence the nature of data that is to be collected because respondents also have their own system of values. There is a high temptation to think that one research approach is 'better' than the other, but this is not true because different philosophies are 'better' at doing different things. Which is 'better' partly depends on the question(s) one seeks to answer in his or her research. Only if we understood each philosophy and its assumptions would we be able to challenge them. This paper has not provided scientifically sacrosanct debate, but has simply added to the general ongoing academic confrontations around the use of philosophy in scientific research. ${ }^{\text {Researchers }}$ are therefore challenged to engage critically with the thoughts provided in this paper for continuity of debates and evolvement of ideas.

\section{Concluding Thoughts}

Premised on the debates provided in the main text, it can be concluded that the moral and scientific correctness of any scientific research is more a function of the philosophical soundness of the methodologic and analytic decisions than merely the length and its content. The paper has also argued that mere recitation, repetition and dumping of borrowed words without careful re-contextualization of onto-epistemic assumptions to one's own scientific research does not guarantee the quality and relevance of the philosophical lens adopted in a research. The paper has also shown that relevance of a particular paradigm depends on the question(s) a research seeks to address.

\section{REFERENCES}

[1] Bates, N. (1977). Epistemology in Research. New York: Prentice Hall.

[2] Bhaskar, R. (2012). Critical Realism. Cape Town: np.

[3] Bless, R. and Achola, H. (1990). Social Research Methods. London: Oxford Press.

[4] Burr, J.R. and Goldinger, M (2012). Philosophy and Contemporary Issues. $9^{\text {th }}$ Ed. New Delhi: PHI Learning Private Ltd.

[5] Cohen, L., Lawrence, M. and Morrison, K. (2000). Research Methods in Education (5th Ed.). London: n.p.

[6] Guba, E.G. (1990). The Paradigm Dialogue. New York: Sage.

[7] Keeney, O. (1983). Epistemology. London: McGraw Hill.

[8] Lichbach, J. (2007). Competing Paradigms. London: Sage.

[9] Lotz-Sisitka, H., Fien, J. and Ketlhoilwe, M. (2013). "Traditions and New Niches: An Overview of Environmental Research". In Stevenson, R., Brody, M. Dillon, J. and Wals, A. (eds.) Hand Book of Research on Environmental Education. New York: Routeledge.

[10] Makumba, M.M. (2009). Introduction to Philosophy. Nairobi: Paulines Publications Africa.

[11] O’Leany, C. (2004). Social Science Research. London: Sage.

[12] Price, L. (2013). Naked Science: Avoiding Methodolatry in an Scientific research Context. Southern African Journal of Environmental Education. Vol. 29. Pp. 10-24.

[13] Saunders, M., Lewis, P. and Thornhill, A. (2007). Research Methods for Business Students. London: Prentice Hall.

[14] Taneja, V.R. (2008). Educational Thought and Practice. New Delhi: Sterling Publishers.

[15] Namafe C., Muchanga M. (2017). The Relation of Mainstreamed Environmental Education to the Modern Schooling System in Zambia. In: Lotz-Sisitka H., Shumba O., Lupele J., Wilmot D. (eds) Schooling for Sustainable Development in Africa. Schooling for Sustainable Development. Springer, Cham

Citation: Manoah Muchanga. "Reflexive Debate on Use of Philosophy in Scientific Research" International Journal of Humanities Social Sciences and Education (IJHSSE), vol 7, no. 6, 2020, pp. 208-213. doi: http://dx.doi.org/10.20431/2349-0381.0706022.

Copyright: () 2020 Authors. This is an open-access article distributed under the terms of the Creative Commons Attribution License, which permits unrestricted use, distribution, and reproduction in any medium, provided the original author and source are credited. 